\title{
Inelastic Displacement Ratio Spectrum for Near-Fault Ground Motions
}

\author{
Gaylord Kabongo-Booto and George D. Hatzigeorgiou
}

\begin{abstract}
This paper examines the spectrum of inelastic displacement ratio (IDR) for structures subjected to near-fault earthquakes. IDR can be defined as the ratio of the maximum inelastic to the maximum elastic displacement of a structure and allows the computation of its maximum inelastic displacement directly from the corresponding elastic counterpart. Extensive parametric analyses are carried out to obtain empirical expressions for this ratio, in terms of the period of vibration and ductility demands.
\end{abstract}

Index Terms-Inelastic displacement ratio spectrum, seismic analysis, ductility demands, near-fault earthquakes.

\section{INTRODUCTION}

This study develops a simple and efficient method for the evaluation of inelastic displacement ratio (IDR) spectrum. Knowledge of IDR, i.e. the ratio of the maximum inelastic to the maximum elastic displacement of a structure, allows the computation of its maximum inelastic displacement directly from the corresponding elastic counterpart. Veletsos [1], Veletsos and Newmark [2] and Clough [3] found that in the low-frequency range of the spectrum, the maximum displacement of an inelastic system may be considered the same as the maximum displacement of the associated elastic system, according to the so-called 'equal-displacement rule'. Nonetheless, Miranda [4] and Chopra and Chintanapakdee [5] observed that IDR can differ considerably from unity in the moderately high to high frequency regions of spectrum. Furthermore, Hatzigeorgiou and Beskos [6] found that repeated earthquakes significantly affect the inelastic displacement ratio.

It is worth noticing that most of the seismic codes assumed far-fault earthquakes to describe the seismic loads. However, an earthquake that recorded closely to its fault at a station located toward the direction of the fault rupture is qualitatively quite different from the usual far-fault seismic records [7]. The categorization and analytical representation of near-fault earthquakes as well as the study of their effects on the seismic behavior of structures are very important research topics today. On e can mention here the works of Makris [8], Makris and Chung [9], Zhai et al., [10], Ruiz-Garcia [11] and Iervolino et al. [12]. Although the development that has been accomplished so far, there is still a clear need to understand the behavior of structures subjected to near-source seismic ground motions. Thus, this study

Manuscript received May 15, 2013; revised July 1, 2013.

The authors are with the Department of Environmental Engineering, Democritus University of Thrace, GR 67100 Greece (e-mail: gaylkabo@env.duth.gr, gchatzig@env.duth.gr). focuses on the evaluation of inelastic displacement ratio (IDR) spectrum of structures subjected to near-fault earthquakes. Without loss of generality, elastic - perfectly plastic models are adopted. These models are simple and can adequately describe steel or reinforced concrete structures with primarily flexural behavior. The influence of period of vibration and ductility demands are taken into account in constructing expressions for the IDR through extensive parametric studies and nonlinear regression analysis. A statistical investigation of 72,000 inelastic time-history analyses are carried out to study 200 SDOF models with 6 levels of ductility demands, excited by 60 earthquake accelerogram records from around the world, under various types of faults mechanisms such as strike-slip, reverse or oblique-reverse.

\section{DESCRIPTION OF MODEL}

An elastic - perfectly plastic SDOF system with viscous damping is used to model the structure, as shown in Fig. 1. The dynamic equilibrium equation of this system is given by

$$
m \ddot{u}+c \dot{u}+k^{T} u=-m a_{g}
$$

where $m$ is the mass, $u$ the relative displacement, $c$ the damping coefficient, $k^{T}$ the tangent stiffness, $a_{g}$ the acceleration of the ground motion while upper dots stand for time derivatives.

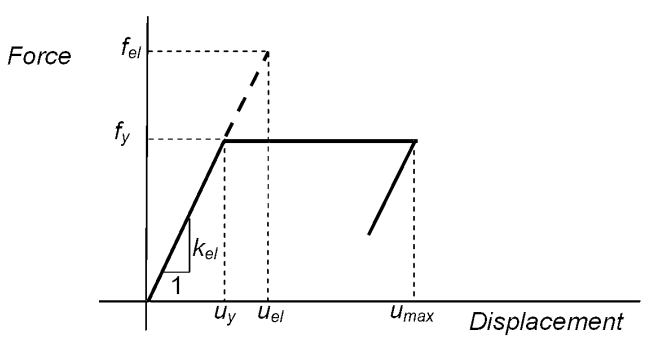

Fig. 1. Elastic - perfectly plastic model of a SDOF.

Using structural dynamics theory [6], these systems are defined here by their elastic vibration period $T$, ranging from $0.02 \mathrm{sec}$ to $4.0 \mathrm{sec}$, and viscous damping ratio, $\xi$, assumed to be $5 \%$. The yield force $f_{y}$ can be expressed in terms of the yield displacement $u_{y}$ and the elastic stiffness $k_{e l}$ as

$$
f_{y}=k_{e l} \cdot u_{y}
$$

While the ductility $\mu$ is defined in terms of the maximum displacement $u_{\max }$ and the yield displacement $u_{y}$, as 


$$
\mu=\frac{u_{\max }}{u_{y}}
$$

Finally, the inelastic displacement ratio is defined as the maximum lateral inelastic displacement $u_{\max }$ divided by the maximum lateral elastic displacement $u_{e l}$ for a system with the same mass and initial stiffness (i.e., same period of vibration) subjected to the same earthquake ground motion. This ratio is given by

$$
I D R=\frac{u_{\max }}{u_{e l}}
$$

\section{SEISMIC INPUT}

The seismic excitations that have been used in this work consist of 60 pulse-like ground motions recorded closely to faults with strike-slip, reverse or oblique-reverse mechanisms. The examined near-fault ground motions, which have been recorded at a distance less than $10 \mathrm{~km}$ from the fault rupture, are characterized by intense velocity pulses of relatively long period that clearly distinguish them from typical far-field ground motions. The aforementioned 60 seismic records have been downloaded from the NGA-PEER strong ground motion database [13]. The complete lists of the

\begin{tabular}{|c|c|c|c|}
\hline Earthquake & Year & Station & Magn. $\mathrm{M}_{\mathrm{w}}$ \\
\hline Cape Mendocino & 1992 & Cape Mendocino & 7.01 \\
\hline Cape Mendocino & 1992 & Petrolia & 7.01 \\
\hline Chi-Chi, Taiwan & 1999 & CHY006 & 7.62 \\
\hline Chi-Chi, Taiwan & 1999 & CHY035 & 7.62 \\
\hline Chi-Chi, Taiwan & 1999 & TAP003 & 7.62 \\
\hline Chi-Chi, Taiwan & 1999 & TAP005 & 7.62 \\
\hline Chi-Chi, Taiwan & 1999 & TCU036 & 7.62 \\
\hline Coalinga-05 & 1983 & Oil City & 5.77 \\
\hline Coalinga-05 & 1983 & Transmitter Hill & 5.77 \\
\hline Coalinga-07 & 1983 & Coalinga- $14^{\text {th }}-$ Elm & 5.21 \\
\hline Erzican, Turkey & 1992 & Erzincan & 6.69 \\
\hline Imperial Valley & 1979 & Aeropuerto Mexicali & 6.53 \\
\hline Imperial Valley & 1979 & Agrarias & 6.53 \\
\hline Imperial Valley & 1979 & Brawley Airport & 6.53 \\
\hline Imperial Valley & 1979 & Meloland Overpass FF & 6.53 \\
\hline Imperial Valley & 1979 & El Centro Array \#10 & 6.53 \\
\hline Imperial Valley & 1979 & El Centro Array \#6 & 6.53 \\
\hline Imperial Valley & 1979 & El Centro Array \#8 & 6.53 \\
\hline Imperial Valley & 1979 & Holtville Post Office & 6.53 \\
\hline
\end{tabular}
aforementioned earthquakes are shown in Table I.

\section{ANALYSIS}

For each earthquake record, the period of the SDOF system is increased from 0.02 to $4.0 \mathrm{sec}$ with an increment of
$0.02 \mathrm{sec}$ (i.e., 200 values of period), while the ductility demand is assumed to increase from 1.0 to 6.0 with an increment of 1.0 (i.e., 6 values of $\mu$ factors). Thus, 72,000 analyses are examined: (60 ground motions $) \times(200$ periods, $T) \times(6$ levels of ductility demands, $\mu)$. Every analysis serves to solve the nonlinear differential Eq. (1) by Newmark method and determine the response $u(t)$ in terms of various parameters of the problem.

\begin{tabular}{|c|c|c|c|}
\hline Earthquake & Year & Station & Magn. $\mathrm{M}_{\mathrm{w}}$ \\
\hline Kobe, Japan & 1995 & KJMA & 6.90 \\
\hline Kobe, Japan & 1995 & Takarazuka & 6.90 \\
\hline Kobe, Japan & 1995 & Takatori & 6.90 \\
\hline Kocaeli, Turkey & 1999 & Arcelik & 7.51 \\
\hline Kocaeli, Turkey & 1999 & Yarimca & 7.51 \\
\hline Landers & 1992 & Lucerne & 7.28 \\
\hline Landers & 1992 & Yermo Fire Station & 7.28 \\
\hline Loma Prieta & 1989 & Alameda NA Stn Hanger & 6.93 \\
\hline Loma Prieta & 1989 & Gilroy - Gavilan Coll. & 6.93 \\
\hline Loma Prieta & 1989 & Gilroy - Historic Bldg. & 6.93 \\
\hline Loma Prieta & 1989 & Gilroy Array \#2 & 6.93 \\
\hline Loma Prieta & 1989 & LGPC & 6.93 \\
\hline Loma Prieta & 1989 & Oakland - Outer Harbor & 6.93 \\
\hline Loma Prieta & 1989 & Oakland - Title \& Trust & 6.93 \\
\hline Mammoth Lakes & 1980 & L. Valley Dam (Upr L) & 5.94 \\
\hline Morgan Hill & 1984 & Coyote Lake Dam (SW) & 6.19 \\
\hline Morgan Hill & 1984 & Gilroy Array \#6 & 6.19 \\
\hline Nahanni, Canada & 1985 & Site 2 & 6.76 \\
\hline Northridge & 1994 & LA - Wadsworth Hosp. & 6.69 \\
\hline Northridge & 1994 & LA Dam & 6.69 \\
\hline Northridge & 1994 & Newhall - Fire Sta & 6.69 \\
\hline Northridge & 1994 & Newhall - W Pico C. Rd. & 6.69 \\
\hline Northridge & 1994 & Pacoima Dam (downstr) & 6.69 \\
\hline Northridge & 1994 & Pacoima Dam (up. left) & 6.69 \\
\hline Northridge & 1994 & Rinaldi Receiving Sta & 6.69 \\
\hline Northridge & 1994 & Sylmar - Converter Sta E. & 6.69 \\
\hline Northridge & 1994 & Sylmar - Olive View Med & 6.69 \\
\hline N. Palm Springs & 1986 & North Palm Springs & 6.06 \\
\hline San Salvador & 1986 & National Geografical Inst & 5.80 \\
\hline Superstition Hills & 1987 & El Centro Imp. Co. Cent & 6.54 \\
\hline Superstition Hills & 1987 & Kornbloom Road (temp) & 6.54 \\
\hline Superstition Hills & 1987 & Parachute Test Site & 6.54 \\
\hline Westmorland & 1981 & Parachute Test Site & 5.90 \\
\hline Westmorland & 1981 & Westmorland Fire Sta & 5.90 \\
\hline Whittier Narrows & 1987 & LB - Orange Ave & 5.99 \\
\hline Yountville & 2000 & Napa Fire Station \#3 & 5.00 \\
\hline
\end{tabular}

TABLE I: CONTINUED

A comprehensive nonlinear regression analysis is 
performed on the basis of the data obtained by the aforementioned response analyses. Thus, the following empirical expression for $I D R-T-\mu$ is obtained

$$
\operatorname{IDR}(T, \mu)=1+(\mu-1)^{c_{1}}\left(\frac{c_{2}}{T^{c_{3}}}+c_{4}\right)
$$

This empirical expression was one of the simplest equations which better described the numerical data following downward and upward concave curves, obtained by a homemade program after testing hundreds of simple mathematical equations. More specifically, this program fits about one thousand of built-in equations and then ranks them with respect to the corresponding correlation factor between the 'exact' and 'predicted' results. Coefficients $c_{1}-c_{4}$ should be evaluated in order to minimize to divergence between the results of 'exact' dynamic inelastic analysis and those of empirical Eq. (5). This leads to the following expression

$$
\operatorname{IDR}(T, \mu)=1+(\mu-1)^{1.10}\left(\frac{0.16}{T^{0.45}}-0.11\right)
$$

where the correlation coefficient is $R^{2}=0.964$ and the standard deviation is $\sigma=0.055$.

\section{COMPARISON WITH 'EXACT' RESUltS AND OTHER STUDIES}

This section examines the effectiveness and accuracy of the proposed empirical Eq. (6) for the evaluation of inelastic displacement ratios. Furthermore, comparisons of the proposed method with other existent studies from the pertinent literature are also provided. Thus, Fig. 2 shows the whole set of results for the aforementioned 72,000 analyses using the proposed method versus the 'exact' results of dynamic inelastic analyses.

It is found that the proposed empirical expression can accurately evaluate the inelastic displacement ratios for structures subjected to near-fault earthquakes. This can also be observed examining inelastic displacement ratio spectra for specific ground motions. For example, Fig. 3 shows the IDR spectrum for a SDOF system with $\mu=4$, subjected to Palm Springs Earthquake (07/08/1986). It is obvious that empirical Eq. (6) closely follows the 'exact' dynamic inelastic analyses results.

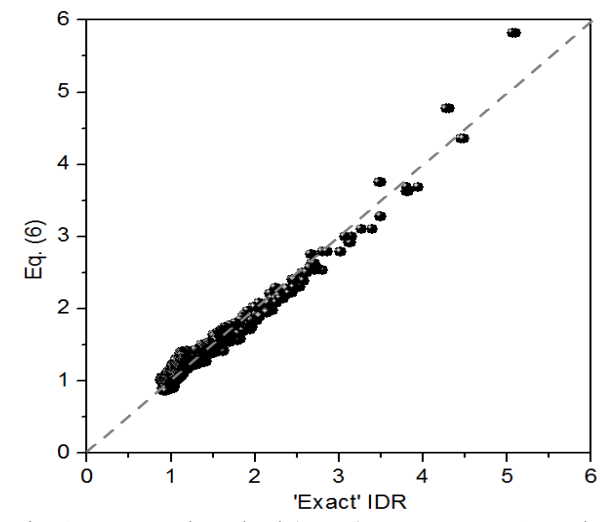

Fig. 2. Proposed method (Eq. 6) versus 'exact' results.

Miranda [14] proposed another empirical expression for the evaluation of inelastic displacement ratio, in the form

$$
\operatorname{IDR}(T, \mu)=\left[1+\left(\frac{1}{\mu}-1\right) \exp \left(-12 T \mu^{-0.8}\right)\right]^{-1}
$$

It is worth noticing that Eq. (7) has been proposed for traditional far-field seismic records and it is examined here to compare the structural response under far-field and near-fault ground motions. Thus, Fig. 4 presents the analyses results using the aforementioned empirical expression of Miranda [14] versus the 'exact' results of dynamic inelastic analyses.

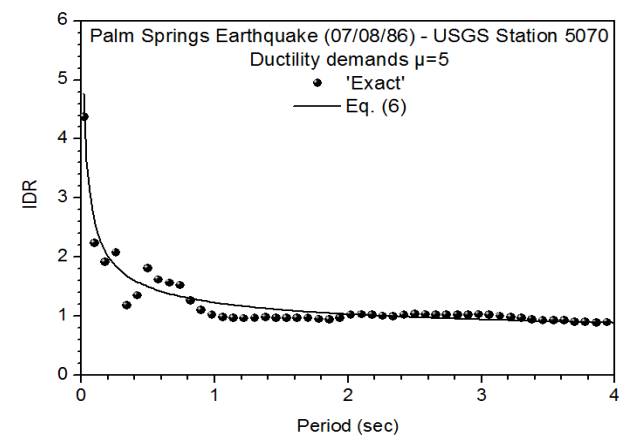

Fig. 3. IDR spectrum for Palm Springs Earthquake (07/08/1986).

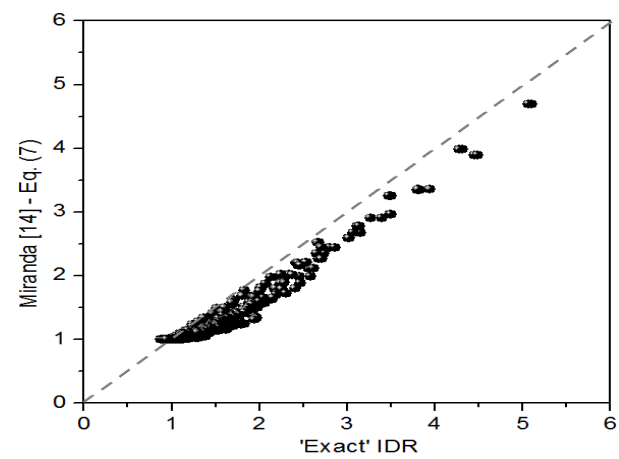

Fig. 4. Miranda's approach [14] (Eq. 7) versus 'exact' results.

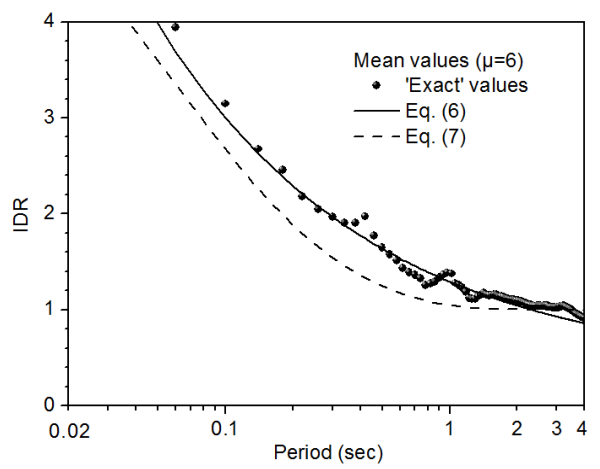

Fig. 5. Empirical Eqs (6) and (7) versus 'exact' results for $\mu=6$.

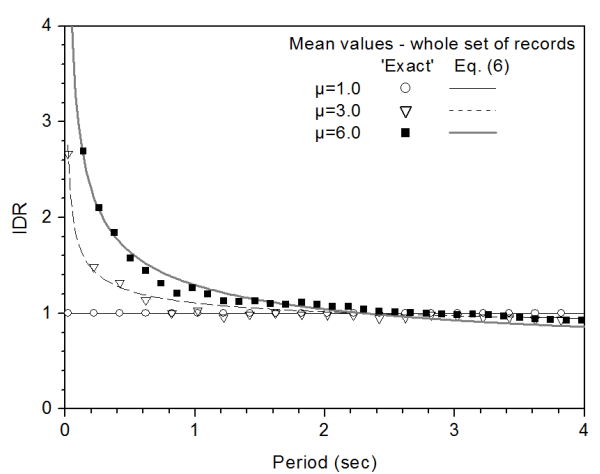

Fig. 6. Influence of ductility demands on $I D R$ 
Examining Fig. 4, it can be observed that almost the whole set of results appears to be under the diagonal of the diagram. This behavior means that near-fault ground motions generally lead to higher values of inelastic displacement ratios in comparison with far-field seismic records. This is also obvious in Fig. 5, which depicts the IDR mean 'exact' values (for the whole set of records) for $\mu=6$, as well as the values from the proposed method (Eq. 6) and the approach of Miranda [14] (Eq. 7).

Furthermore, it is obvious that the inelastic displacement ratio is strongly affected by the period of vibration, where the higher the period the lower the IDR. Additionally, Fig. 6 shows that inelastic displacement ratios are also influenced by ductility demands.

It is found that, generally, the higher the level of ductility demands the higher the IDR.

\section{CONCLUSIONS}

This study proposes a new method for evaluating inelastic displacement ratios of SDOF systems subjected to near-fault earthquakes on the basis of empirical expressions obtained after extensive parametric studies. The influence of period of vibration and ductility demands are carefully examined and discussed. A detailed study of the influence of the various parameters of the problem on the inelastic displacement ratio leads to the following conclusions:

1) The increase of ductility demands always leads to increased inelastic displacement ratios and vice versa. Furthermore, these ratios extremely depend on the structural period of the SDOF system, especially in the short-period range, say up to $1.0 \mathrm{sec}$. In this case, the lower the period, the higher the inelastic displacement ratio.

2) Near-fault seismic records lead to different inelastic displacement ratios in comparison with traditional far-field ground motions. More specifically, the former type of records leads to higher values of IDR in comparison with the latter one, especially in the short-period range, say up to $1.0 \mathrm{sec}$. Therefore, the pulse character of near-fault records should be taken into account.

3) Theoretical background examining all the parameters and characteristics of mechanisms of seismic faults, i.e., reverse, strike-slip, oblique-reverse etc., as well as appropriate empirical expressions for the corresponding inelastic displacement ratios are currently being derived and will be presented in a future paper by the authors.

\section{REFERENCES}

[1] A. S. Veletsos, "Maximum deformations of certain nonlinear systems," in Proc. of $4^{\text {th }}$ World Conf. on Earthquake Eng., Chilean Association on Seismic and Earthquake Engineering, vol. II, Santiago, Chile, A4-155-A4-170, 1969.

[2] A. S. Veletsos and N. M. Newmark, "Effect of inelastic behavior on the response of simple systems to earthquake motions," in Proc. of $2^{\text {nd }}$
World Conf. on Earthquake Eng., Science Council of Japan: Tokyo, Japan 1960, pp. 895-912.

[3] R. W. Clough. "Effect of stiffness degradation on earthquake ductility requirements," Rep. No. SEMM 66-16, Dept. of Civil Engineering, Univ. of California at Berkeley, Berkeley, California, 1966.

[4] E. Miranda, "Inelastic displacement ratios for structures on firm sites," J. Struct. Eng. ASCE, vol. 126, no. 10, pp. 1150-1159, 2000.

[5] A. K. Chopra and C. Chintanapakdee, "Inelastic deformation ratios for design and evaluation of structures: Single-degree-of freedom bilinear systems," J. Struct. Eng. ASCE, vol. 130, no. 9, pp. 1309-1319, 2004.

[6] G. D. Hatzigeorgiou and D. E. Beskos, "Inelastic displacement ratios for SDOF structures subjected to repeated earthquakes," Eng. Struct., vol. 31, pp. 2744-2755, 2009.

[7] A. K. Chopra and C. Chintanapakdee, "Comparing response of SDOF systems to near-fault and far-fault earthquake motions in the context of spectral regions," Earthquake Eng. Struct. Dyn., vol. 30, pp. 1769-1789, 2001.

[8] N. Makris, "Rigidity-plasticity-viscosity: can electrorheological dampers protect base-isolated structures from near-source ground motions?" Earthquake Eng Struct Dyn, vol. 26, pp. 571-591, 1997.

[9] N. Makris and S. P. Chang. "Response of damped oscillators to cycloid pulses," J. Eng. Mech. ASCE, vol. 126, pp. 123-131, 2000.

[10] C. Zhai, S. Li, L. Xie and Y. Sun, "Study on inelastic displacement ratio spectra for near-fault pulse-type ground motions," Earthquake Eng. Eng. Vibr., vol. 6, no. 4, pp. 351-355, 2007.

[11] J. R. Garcìa, "Inelastic displacement ratios for seismic assessment of structures subjected to forward-directivity near-fault ground motions," J. Earthquake Eng., vol. 15, no. 3, pp. 449-468, 2011.

[12] I. Iervolino, E. Chioccarelli, and G .Baltzopoulos, "Inelastic displacement ratio of near-source pulse-like ground motions," Earthquake Eng Struct Dyn, vol. 41, pp. 2351-2357, 2012.

[13] PEER (May 2013). Pacific Earthquake Engineering Research Center. [Online].

Available: http://peer.berkeley.edu/peer_ground_motion_database

[14] E. Miranda, "Inelastic displacement ratios for displacement-based earthquake resistant design," in Proc. of $12^{\text {th }}$ WCEE, Auckland, 2000, paper No. 1096.

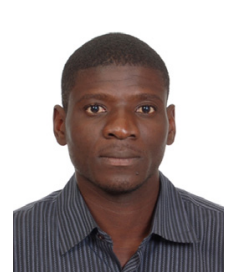

Gaylord Kabongo-Booto was born in Democratic Republic of the Congo. He obtained his diploma in 2005 in Aeronautical Engineering and now he studies Environmental Engineering at the Democritus University of Thrace, Greece.

$\mathrm{He}$ has worked, amongst others, as a system operator (Xanthi, Greece), as well as regional representative and air traffic controller (Kinshasa,

Democratic Republic of the Congo).

Mr. Kabongo-Booto research interests have to do with environmental impacts analysis and analysis / design of structures.

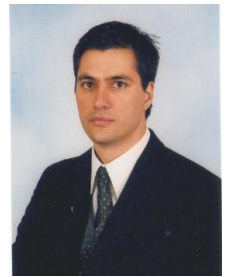

George D. Hatzigeorgiou was born in Athens, Greece. He obtained his diploma in 1995 and his Ph.D. in 2001, both from the Department of Civil Engineering, University of Patras, Greece. His Ph.D. thesis is entitled: Seismic inelastic analysis of underground structures with boundary and finite elements (Advisor: Professor D.E. Beskos). He specialized in the field of Structural Mechanics with

emphasis in Earthquake Engineering.

He worked 11 years as a professional engineer, specializing in design of concrete and steel structures including wind-turbines, large sport-halls, metro stations and high rise buildings. He has been on the faculty of the Department of Environmental Engineering at the Democritus University of Thrace, Greece, since September 2006, specializing in Structural Mechanics. $\mathrm{He}$ is the author of a monograph (e-book) on the Seismic Design of Structures and he has published four chapters in books, over thirty five articles in refereed journals, and more than sixty papers in conference proceedings.

Prof. Hatzigeorgiou is a registered Civil Engineer in Greece and member of Technical Chamber of Greece. He has served as a reviewer of more than 16 journals and has more than 330 citations from other research groups. 